Transhumanism and Moral Equality

James Wilson, Keele University

June 27, 2007 


\title{
Transhumanism and Moral Equality
}

\begin{abstract}
Conservative thinkers such as Francis Fukuyama have produced a battery of objections to the transhumanist project of fundamentally enhancing human capacities. This article examines one of these objections, namely that by allowing some to greatly extend their capacities, we will undermine the fundamental moral equality of human beings. I argue that this objection is groundless: once we understand the basis for human equality, it is clear that anyone who now has the sufficient wherewithal to count as a person from the moral point of view will continue to count as one even if others are fundamentally enhanced; and it is mistaken to think that a creature which had even far greater capacities than an unenhanced human being should count as more than an equal from the moral point of view.
\end{abstract}

\section{INTRODUCTION}

Moral egalitarians believe that all moral persons should be treated as equals: none are to be treated as less than equal, and none are to be treated as more than equal. As used by the moral egalitarian, 'moral person' is a term of art, and should be distinguished from the sense of 'person' used in philosophical debates around personal identity. For moral egalitarians, a moral person just is a creature that has the right features to count as an equal from the moral point of view: moral personhood in this sense neither implies personhood in the sense that the personal identity theorist 
is interested in, nor is implied by it, despite the evident closeness of the two concepts. ${ }^{1}$

In this paper I defend moral egalitarianism against the objection that creatures with greatly superior capacities should be treated as more than equals. I argue that once a creature has the capacities to reach the appropriate standard for moral personality, ${ }^{2}$ that creature ought to be a considered as an equal to all other moral persons, regardless how superior in capacities any other creatures may be. This conclusion is important because it undercuts the moral egalitarian objections to human enhancement that writers such as Francis Fukuyama have advanced. If the argument of this paper is correct, no enhancements we could make to human beings could do anything to undermine the moral status of the unenhanced. Hence if the project of human enhancement presents us with a moral problem, it cannot be that it will undermine our status as moral equals.

The rest of this paper falls into four sections. Section 2 introduces Fukuyama's argument for the claim that human enhancement would undermine the equal moral status of all persons. The next three sections answer this argument. Section 3 argues that Rawls has put forward a plausible account of the sufficient conditions for moral personality (namely what he calls the 'two moral powers'), and assuming this account is correct, even if some human beings became massively enhanced, the unenhanced would retain the two moral powers, and hence would always still count as moral persons. However this account as stated does not yet make it clear why it would be wrong to think of the enhanced as more than equals. The remaining two sections aim to remedy this deficit: section 4 argues that we should think of the properties which make creatures moral persons as threshold properties, namely as properties which are significant as regards to moral status only up to the point where the threshold of moral personality has been reached. Section 5 argues (against an objection from Arneson) that it is not arbitrary to treat the two moral powers as threshold properties. It is not arbitrary to do so because moral persons are appropriately valued as ends in

1 For example, most moral egalitarians claim that newborns should count as moral persons despite the fact that newborns are not plausibly regarded as persons in the personal identity sense. In addition, some moral egalitarians would wish to deny the status of a moral person to creatures which were persons in the personal identity sense, but which had no capacity whatsoever for caring for the wellbeing of others.

Where I use the term 'person' in the rest of this article, I should be understood to be referring to moral persons.

2 I use 'moral personality' to refer to the state of being a moral person. 
themselves, and one person cannot be more of an end in themselves than another. Hence once we get clear about what it is to treat one another as equals, there is no possibility of someone being more than an equal in the relevant sense: every moral person can and should esteem themselves to be on a footing of equality with every other moral person, whether those persons are human, posthuman or nonhuman.

\section{FUKUYAMA'S WORRY ABOUT EQUALITY}

Francis Fukuyama has repeatedly argued that human beings with greatly enhanced capacities would threaten the equal moral status of the unenhanced. His argument for this claim implies that, contrary to what most moral egalitarians believe, the equality of human beings rests on the contingent fact that all human beings share the same human nature, and that hence were we to make fundamental alterations to human nature (as transhumanists ${ }^{3}$ advocate doing), there would no longer be any basis for moral egalitarianism:

The political equality enshrined in the Declaration of Independence rests on the empirical fact of natural human equality... Underlying this idea of the equality of rights is the belief that we all possess a human essence that dwarfs manifest differences in skin color, beauty, and even intelligence. This essence, and the view that individuals therefore have inherent value, is at the heart of political liberalism. But modifying that essence is the core of the transhumanist project. If we start transforming ourselves into something superior, what rights will these enhanced creatures claim, and what rights

3 Transhumanists believe that 'the human species in its current form does not represent the end of our development but rather a comparatively early phase,' and they affirm 'the possibility and desirability of fundamentally improving the human condition through applied reason, especially by developing and making widely available technologies to eliminate aging and to greatly enhance human intellectual, physical, and psychological capacities.' N. Bostrom. 2003. The Transhumanist FAQ. Available at: www.transhumanism.org/resources/faq.html [Accessed 20 December 2006]. 
will they possess when compared to those left behind? ${ }^{4}$

The reference to a 'human essence', is, I suggest unfortunate, and does little, if anything to explain or justify Fukuyama's underlying worry. For in foregrounding the idea of a human essence, Fukuyama commits himself to the following structure of argument:

1. There is a human essence.

2. This human essence is responsible for our equal moral status.

3. This human essence would be changed if we were to enhance ourselves in various ways. 4. Therefore if we enhance ourselves in various ways we will no longer all be of equal moral status.

However, the combination of (2) and (3) is strikingly implausible. ${ }^{5}$ In order for the human essence to be something which could plausibly be lost by the types of enhancements which transhumanists recommend, it would have to be tightly linked to the very particular features and capacities that human beings in fact now have. But it is implausible to think that these very particular features and capacities could be necessary to have the status of a moral equal (for this would rule out a priori the possibility of nonhumans who could count as moral equals). ${ }^{6}$ And moreover, even if the 'human essence' were what explains the moral equality of all current humans, why would the equality of the unenhanced with the enhanced be threatened by the enhanced's departure from this essence?

However, leaving on one side the idea of the human essence, Fukuyama has put his finger on a type of worry for moral egalitarianism. Fukuyama's worry could be rephrased as that the enhanced will not only think of themselves as superior to the ordinary unenhanced human beings, but will also be superior, and this superiority will be in some sense bad. There are two senses in which the

4 F. Fukuyama. Transhumanism. Foreign Policy Sep/Oct 2004; F. Fukuyama. 2002. Our Posthuman Future: Consequences of the biotechnology revolution. New York: Farrar Straus Giroux: 9.

5 As Bostrom points out, (1) is also be rather difficult to justify in the context of a post-Darwinian conception of human beings. (N. Bostrom. In Defense of Posthuman Dignity. Bioethics 2005.)

6 Ibid. 
enhanced might be superior, and only in one of these senses would enhancement raise issues of equal moral status. For the enhanced could be (a) superior in terms of talents, intelligence, ability to control their emotions and so on, whilst still being the moral equals of the ordinary unenhanced human beings, or (b) superior in talents, intelligence, ability to control their emotions and so on in such a way that they were superior from the moral point of view. If the superiority of the enhanced were confined to (a) then it would not be true to say that human enhancement threatened the equal moral status of human beings: for the problem enhancement would create would be one of justice between those of equal moral status but unequal talents and capacities, not a problem of creating beings of a higher moral status than unenhanced human beings. We already face great differences in talents, intelligence, ability to control emotions and so on between human beings as we now find them. Enhancement would magnify the range of these differences, but it would not threaten to undermine moral egalitarianism itself. ${ }^{7}$

Fukuyama's worry is best interpreted as (b): namely that the enhanced will indeed be more than moral equals to the unenhanced, and that given that the enhanced will be the moral superiors of the unenhanced it will be right and proper if enhanced people treat unenhanced people's lives as less important from the moral point of view, and treat the unenhanced as susceptible to being treated merely as means to their ends.

I shall argue that Fukuyama is wrong to be worried about the prospect that future enhanced transhumans or posthumans will be more than our moral equals: indeed, I shall argue that no possible enhancement could render someone more than the moral equal of a standard human being. ${ }^{8}$

\section{THE TWO MORAL POWERS ARE SUFFICIENT CONDITIONS FOR MORAL}

7 This is not to say that the problems of justice caused by allowing some to massively enhance their capacities would be easy to solve, but merely to point out that they would be problems of justice between those of equal moral status, rather than problems of differential moral status.

8 I am going to argue that it is impossible for the enhanced to be of a higher moral status than unenhanced human beings. But as a side issue it is worth asking whether even if per impossible enhanced human beings were superior in moral status to unenhanced human beings, this could constitute a moral, rather than a self-interested objection to their creation. If such beings really were intrinsically more morally valuable than ordinary human beings why would it be immoral to create them? Why wouldn't the unenhanced's objection simply be a self interested attempt to defend their current advantages? 


\section{PERSONALITY}

Whether it is possible for a creature to be more than the equal of an unenhanced human being will depend on what the correct justification is for the equal moral status of human beings. Accounts of moral equality differ on two axes: they differ both in the qualities which are picked out as being necessary and sufficient for the equal moral status of human beings, and also in the way these qualities are believed to function.

In this article I shall not attempt to put forward an account of the necessary conditions for equal moral status. The argument I shall put forward against Fukuyama depends only on our ability to isolate some properties which would be sufficient for moral personality. ${ }^{9}$ My basic argument will be that (1) that there is a set of features which ordinary human beings now have which are very plausibly regarded as sufficient to count as a moral person, and (2) that these features are not capable of giving anyone a higher moral status if they have more than the threshold amount of them, and (3) therefore regardless of how much greater in capacities an enhanced human being may become, they cannot be of a higher moral status than an ordinary unenhanced human being. In this section I shall set out two conditions which I take to be jointly sufficient for moral personality, and to be possessed by the average human being. The next section will aim to justify the claim that possession of these features beyond the minimum amount to count for moral personality will not raise moral status.

I follow Rawls's suggestion that there are two properties which between them are certainly sufficient for a creature to count as a moral person. Rawls calls these conditions the two moral powers. They are, first, a sense of justice: that is, 'the capacity to understand, to apply, and to act from (and not merely in accordance with) the principles of political justice that specify the fair

9 It easier to determine sufficient conditions for being a moral person than necessary conditions, as our intuitions about who definitely counts as a moral person are fairly robust, and we can use these intuitions to derive an account of those features which we are fairly sure would be sufficient to count as a moral person. Giving an account of the necessary conditions for moral personality is much more difficult, and requires us to take some difficult decisions concerning where to draw the line for moral personality, as well as addressing the argument from marginal cases. Focusing only on the sufficient conditions will enable us to answer Fukuyama's worry, whilst sidestepping these difficulties. 
terms of social cooperation. ${ }^{10}$ Second is a capacity for a conception of the good: 'the capacity to have, revise, and rationally to pursue a conception of the good. Such a conception is an ordered family of final ends and aims which specifies a person's conception of what is of value in human life, or, alternatively, of what is regarded as a fully worthwhile life.' ${ }^{11}$

If we were to put the two moral powers forward as an account of the necessary conditions for moral personality, then someone might wish to claim that we were not being sufficiently inclusive in our account of moral persons. For there are some categories of human beings (such as newborns or the severely demented) whom many moral egalitarians would want to claim as moral persons despite the fact that they are at best marginal possessors of the two moral powers. However here we are claiming only that if a creature possesses the two moral powers, it counts as a moral person, and hence as a moral equal. I take it that this claim is sufficiently uncontroversial to be assumed without argument. $^{12}$

\section{THE TWO MORAL POWERS AS THRESHOLD PROPERTIES}

There are three kinds of ways in which the two moral powers could function in justifying equality. First, we could think of the two moral powers as features which a creature either has or does not have, but which do not vary by degree. Second, we could think of the two moral powers as threshold properties - properties which do vary by degree, but where differences in the properties are significant only until a certain threshold has been reached. Third, we could think of the two moral powers as properties which both vary by degree and where variations in the property in question continue to be significant for moral status even once the threshold required for moral personality has been reached. Fukuyama's argument presupposes that quality or qualities which are

10 J. Rawls. 2001. Justice as Fairness: a Restatement. London: Harvard University Press: 18-19.

11 Ibid: 19.

12 I take the sufficiency of the two moral powers, once thus clarified, for moral personality to be fairly obvious: for it is (I submit) impossible to imagine a creature which is securely in possession of the two moral powers but which should not be accorded the status of a moral person. 
responsible for moral personality are of the third kind. ${ }^{13} \mathrm{I}$ shall argue that they are of the second kind.

It is very implausible to think of the two moral powers as belonging to the first kind, namely features which do not admit of degree. For as Arneson argues, it is not plausible to think that, for example, the bare ability to set ends could make the difference between being a moral person and not being a moral person:

Consider a being that has little brain power, but over the course of its life can set just a few ends and make just a few choices based on considering two or three simple alternatives. It sets one end (lunch, now) per decade three times over the course of its life. If there is a capacity to set ends, period, not admitting of degrees, this being possesses it. The point is that it is clearly not merely the capacity to set ends, but something more complex that renders a being a person in our eyes. What matters is whether or not one has the capacity to set sensible ends and to pick among alternative end at a reasonable pace, sorting through complex considerations that bear on the choice of ends and responding in a rational way to these considerations. But this capacity, along with any similar or related capacity that might be urged as a substitute for it, definitely admits of degrees. ${ }^{14}$

Hence the moral egalitarian who wishes to oppose Fukuyama's argument must argue that the two moral powers should be interpreted as threshold properties. This is indeed how Rawls suggests

13 If the properties which make human beings equals were to function in either of the other two ways, the fact that some human beings were vastly enhanced could never give any justification for thinking that the enhanced should be treated as more than equals. For if the two moral powers were to function in an 'all or nothing' manner, then by definition you would either have them or you would not, and persons with greater intelligence and so forth would not have the two moral powers to a higher degree. And if the two moral powers were to function as threshold properties, then by definition greater amounts of them would not be significant to moral status once the threshold had been reached.

14 R. Arneson. 1999. What, if anything, renders all humans morally equal? In Peter Singer and his Critics. D. Jamieson ed. Oxford: Blackwell. 
we think of the two moral powers: according to Rawls, you do not need to have these qualities to a high degree to count as a moral person, but only to a certain minimum amount. Once this minimum threshold has been reached, further increases in the two moral powers are not significant as far as moral status goes:

It is sometimes thought that basic rights and liberties should vary with capacity, but justice as fairness denies this: provided the minimum for moral personality is satisfied, a person is owed all the guarantees of justice... while individuals presumably have varying capacities for a sense of justice, this fact is not a reason for depriving those with a lesser capacity of the full protection of justice. Once a certain minimum is met, a person is entitled to equal liberty on a par with everyone else. ${ }^{15}$

In fact, Rawls even claims that we should think of greater capacities with respect to the two moral powers as natural talents, which are unearned by individuals, and the proceeds of which can be fairly redistributed according to the difference principle, rather than as anything which could entitle the person to a higher moral status. ${ }^{16}$

Given the premisses (1) that possession of the two moral powers is sufficient for moral personality, and (4) the two moral powers function as threshold properties, the conclusion that Fukuyama is wrong to think that enhancement could threaten our moral status as equals follows logically:

1. Possession of the two moral powers is sufficient to count as a moral person.

15 J. Rawls. 1999. A Theory of Justice (revised edition). Oxford: Oxford University Press: 443.

16 'A greater capacity for a sense of justice, as shown say in a greater skill and facility in applying the principles of justice and in marshaling arguments in particular cases, is a natural asset like any other ability. The special advantages a person receives for its exercise are to be governed by the difference principle. Thus if some have to a preeminent degree the judicial virtues of impartiality and integrity which are needed in certain positions, they may properly have whatever benefits should be attached to these offices. Yet the application of the principle of equal liberty is not affected by these differences.' Ibid: 443 
2. The unenhanced will retain the two moral powers regardless of whether or not others become enhanced.

3. Therefore the unenhanced will be moral persons regardless of how enhanced or superior others may be.

4. The two moral powers function as threshold properties: amounts of them above the threshold amount are not significant for moral status.

5. Therefore even if enhanced persons have the two moral powers to a higher degree than unenhanced persons, this will not increase the moral status of the enhanced.

6. Therefore any amount of these features above the threshold amount does not render a person more than an equal.

7. Therefore all moral persons are moral equals, and therefore Fukuyama is wrong to think that enhancement could threaten the equal moral status of all persons.

The main potential difficulty with the argument is premiss (4): why should we regard the two moral powers as threshold properties in this way? ${ }^{17}$ Unfortunately, Rawls provides us with no explicit argument as to why we should treat the two moral powers as threshold properties. ${ }^{18}$ But the claim that the two moral powers should be thought of as threshold properties is by no means obviously correct. In Arneson's words:

[Rawls' account] is like an account of moral status that identifies height as the characteristic of living beings that determines their moral status, proclaims that tall is better than short, and identifies beings over six feet tall as the first-class citizens of the moral universe. The story so far is not incoherent, but one needs an answer to this worry: If being taller is better, and tallness determines moral status, why should not being taller than six feet confer a superior moral status over those who are just barely

17 As I said before, I take premiss (1) to be uncontroversially true.

18 As Arneson puts it, 'The difficulty with Rawls's proposal regarding the basis of equality is that no plausible reason is given for regarding the possession of more or less of the Rawls features once one is above the threshold as irrelevant to the determination of one's moral status.' (op. cit: ) 
six feet tall ${ }^{19}$

\section{ANSWERING ARNESON'S OBJECTION}

In this section I shall explain why it is not arbitrary to think that the two moral powers function as threshold properties. I shall argue that the two moral powers' status as threshold properties is justified by the way in which it is appropriate to value moral persons: moral persons should be respected as ends in themselves. Being an end in oneself does not admit of degrees, so it is wrong to think that one could become more of an end in oneself by coming to have a greater amount of the two moral powers than the threshold.

We can distinguish between two types of approach to things which are valuable: promoting and respecting. To promote something valuable is to aim to bring it about that there is more of this valuable thing in the world. To respect something valuable is, primarily, to judge that that there are legitimate limits on what may be done with it, or to it. Items which are appropriately considered to be objects of respect are said to be ends in themselves, to mark the fact that they cannot simply be used as means to whatever ends we may fancy. Items which are not ends in themselves can legitimately be used for whatever purposes we see fit.

Moral egalitarians, I suggest, should gloss moral equality in terms of the idea of respecting persons as ends in themselves. ${ }^{20}$ On this view, while it is true that there are certain things about human beings that we ought to promote (I should promote your happiness, aim to reduce your

19 Ibid. If we were to propose the two moral powers as necessary conditions for moral personality, then it would be difficult to avoid a different worry, namely that there will be a great difference in the treatment appropriate to those above the threshold as compared to those below it, whilst Rawls has given no clear criterion for where we should draw the line. But for our purposes this is not relevant: given that the ordinary adult human being will be well over the threshold line, wherever we decide to draw the threshold, enhancement will not create any additional difficulties here.

20 It is possible to be a moral egalitarian without thinking that persons are ends in themselves: for example, you could think that the aim of morality should be to promote values such as happiness, or freedom from pain overall, and think that moral personality is the necessary feature you need to have in order to count morally speaking. But moral egalitarians who do not believe that persons are ends in themselves will find it difficult to answer Arneson's question. For if our goal is promoting value, then it is unclear why we should most effectively promote this value by treating those with far greater capacities for rational thought, or happiness equally to those with less. 
pain), underlying this is a value that moral persons have which is to be respected rather than promoted. If this is the correct reading of equality, then Arneson's objection would seem to have missed the point: for on this view, the equality lies in the attitude (namely respect) with which each must treat others and with which each may in turn expect to be treated by them, rather than in the possession of an equal amount of any property. Therefore, the idea that increased amounts of a capacity should entitle you to be more than an equal looks to be a nonsequitur.

Given the claim that moral persons are appropriately treated as ends in themselves, and the claim that the equality that the moral egalitarian believes in is fundamentally an attitude of equal respect, due to moral persons because they are moral persons, it follows that we cannot view the qualities which are responsible for giving moral persons their moral status in the way that Fukuyama does. For being an end in yourself is an all or nothing affair: you either are one or you are not. It does not make sense to be more of an end in yourself than someone else, and that therefore even if some have more of the features which are the basis for ascribing them the status of ends in themselves, this provides no reason to think that they are more than equals.

\section{CONCLUSION}

The prospect of human enhancement on a large scale gives us much to worry about. But if what I have argued here is correct, one thing that we should not be worrying about is the prospect that greatly enhanced human beings will be superior in moral status to us. In Kant's words, every moral person 'can measure himself against each member of his species, and can esteem himself on a footing of equality with them. ${ }^{21}$ Transhumanism presents no moral status based worries: rather, the worries that the project of human enhancement raises are problems of justice between those of equal moral status. But it would be wrong to think that these problems are trivial. History shows us that it is very difficult to get people to treat others as equals when they believe the others to be

\footnotetext{
21 I. Kant. 1996. Metaphysics of Morals trans. M. Gregor in Kant, Practical Philosophy. Cambridge, Cambridge
} University Press, 1996: 435 in the Akadamie pagination. 
inferior in intellect and in various other ways to them. ${ }^{22}$ What I have said here does little, if anything to show, that we will be able to overcome these justice based worries: but we are at least now in a position to see them correctly for what they are.

22 L Thomas. (2005) Moral Equality and Natural Inferiority. Social Theory and Practice. 